\title{
FORMAÇÃO DOCENTE PARA O USO DOS APLICATIVOS DO GOOGLE FOR EDUCATION EM SALA DE AULA
}

\author{
EDUCACIÓN DE PROFESORES PARA EL USO DE GOOGLE PARA APLICACIONES \\ DE EDUCACIÓN EN LA SALA DE AULA
}

\section{TEACHER FOR EDUCATION FOR USING THE APPLICATIONS OF GOOGLE FOR EDUCATION IN THE CLASSROOM}

\author{
Alana Danielly VASCONCELOS ${ }^{1}$ \\ Anne Alilma Silva Souza FERRETE ${ }^{2}$ \\ Ivonaldo Pereira de LIMA $^{3}$
}

RESUMO: O trabalho apresentado analisa o processo de formação docente sob a perspectiva do uso dos aplicativos da plataforma Google for Education nas práticas de ensino de uma Instituição de Ensino Superior, do município de Aracaju, SE. Trata-se de uma pesquisa qualitativa, com abordagem descritiva e exploratória e com trabalho de campo. Para produção de dados foi empregado instrumentos de coleta de dados como questionário semiestruturado, e os docentes como público-alvo. A metodologia adotada foi na perspectiva de análise de conteúdo e como resultado constatou-se que apesar dos docentes participantes da pesquisa, dois fatores se mostram essenciais para o uso eficaz das TDIC no processo de aprendizagem: interesse e investimento em formação continuada.

PALAVRAS-CHAVE: Educação. Aplicativos. Formação docente.

RESUMEN: El presente trabajo demuestra el analisis del proceso de capacitación de profesores desde la perspectiva del uso de aplicaciones en la plataforma digital 'Google for Education' en las prácticas docentes de una institución de educación superior, en la ciudad de Aracaju (Brasil). Con un enfoque descriptivo y exploratorio y con trabajo de campo, una investigación de sentido cualitativo fue desarollada. Instrumentos de recopilación de datos se utilizaron para la producción de datos tales como cuestionarios semiestructurados y el profesorado - como público objetivo. La metodología adoptada tuvo que ver con la perspectiva del análisis de contenido y, como resultado, se encontró que, a pesar de los docentes que participan en la investigación, dos factores son esenciales para el uso eficaz de las 'TDIC' en el proceso de aprendizaje: el interés así como la inversión en educación/formación continua.

\footnotetext{
${ }^{1}$ Universidade Federal de Sergipe (UFS), São Cristóvão - SE - Brasil. Professora Adjunta nos Cursos de Graduação (FSLF). Doutoranda em Educação no Programa de Pós-Graduação em Educação (UFS). ORCID: http://orcid.org/0000-0001-7097-9478. E-mail: alana.vasconcelos@hotmail.com

${ }^{2}$ Universidade Federal de Sergipe (UFS), São Cristóvão - SE - Brasil. Professora Associada do Departamento de Educação e Professora Permanente do Programa de Pós-Graduação em Educação. Doutora em Educação (UFRN). ORCID: http://orcid.org/0000-0001-9637-6616. E-mail: alilma.ferrete50@gmail.com

${ }^{3}$ Universidade Federal de Sergipe (UFS), São Cristóvão - SE - Brasil. Professor da Rede Pública de Ensino do Estado de Alagoas. Doutorando em Educação no Programa de Pós-Graduação em Educação (UFS). ORCID: https://orcid.org/0000-0003-4748-3348. E-mail: ivonaldopereiralima@bol.com.br
} 
PALABRAS CLAVE: Educación. Aplicaciones. Formación docente.

ABSTRACT: This paper analyzes the process of teacher training under a perspective of using apps from Google Education Plataform in Higher Education Institutions, in Aracaju/SE. This is a qualitative research, with a descriptive and exploratory approach within a field work. Concerning the instrument of data collection, it has been chosen a semistructured research, and teachers were the target audience. The methodology adopted aimed the perspective of content analysis and results for the learning of the participants of the research, with two important factors for the learning of the Digital Information Communication Technology in the learning process: interest and investment in continuing education.

KEYWORDS: Education; Applications; Teacher training.

\section{Introdução}

As Tecnologias Digitais de Informação e Comunicação (TDIC) estão conquistando cada vez mais espaço na educação. Com o advento da tecnologia houve uma reconfiguração da forma de organização social e profissional, bem como com a maneira das pessoas se comunicarem e relacionarem. Diante de tantas mudanças o professor precisa refletir sobre suas práticas em sala de aula e buscar formas alternativas de se qualificar para que sua prática esteja em conexão com a práxis social dos estudantes, uma vez que as TDIC estão possibilitando novas oportunidades de aprendizagem tanto para o professor quanto para o aluno.

Desta forma, não resta dúvidas de que a utilização das tecnologias digitais vem sendo muito discutida no contexto educacional formal e trazendo mudanças não só curriculares, mas na prática pedagógica, metodológica do docente em todos os níveis de ensino. Pois, de acordo com Prensky (2001), as crianças e jovens que se encontram em sala de aula nos dias de hoje não são mais as mesmas de outrora. São o que Prensky (2001) intitulou de nativos digitais, ou seja, são aquelas pessoas que já nascem na era digital e tem muita facilidade de manuseio das TDIC.

Diante do exposto, cabe ao docente, em constante formação, atualizar-se perante sua prática pedagógica em sala de aula, aprender e utilizar estas ferramentas digitais, a fim de dar um significado pedagógico a essas ferramentas utilizadas por seus alunos quase que diariamente no âmbito educacional, independentemente do nível de formação em que atue.

Essas ferramentas digitais nos levam a pensar questões inerentes à formação de professores para que façam uso das tecnologias digitais em sala de aula, de maneira a 
contribuir no processo de ensino e aprendizagem privilegiando desenvolvimento intelectual e cultural dos estudantes. Entendemos que é na formação inicial dos professores em que o uso das tecnologias precisa ser trabalhado para que no exercício profissional o professor possa fazer uso de boas práticas de ensino com a inserção das TDIC.

Asseveramos deste modo que a formação inicial bem consolidada poderá representar o fortalecimento para a educação, permitindo maior autonomia ao professor no uso dos aplicativos tecnológicos digitais, implementando sua prática e, até mesmo, utilizando para sua própria formação continuada.

Neste contexto, várias empresas vêm investindo na criação de aplicativos educacionais. O Google, por exemplo, é conhecido no mundo todo e, no Brasil, o mesmo vem conquistando os espaços formais, as instituições de ensino em seus diversos níveis, bem como nos ambientes informais, rodas de amigos, na família, entre outros. Considerando que o navegador do Google é uma das ferramentas mais utilizadas no tocante às buscas por informações de maneira ágil na internet, vemos que não é só o omnibox ${ }^{4}$ do Google que atrai os brasileiros. Os aplicativos (Apps) do Google vêm sendo cada vez mais frequentes no âmbito das escolas públicas e privadas do Brasil.

Neste artigo, optou-se por analisar como acontece a formação docente para o uso dos aplicativos da plataforma intitulada de "Google for Education", ou seja, "Google para Educação", e qual os desafios e possibilidades desses Apps no ambiente escolar. Analisou-se aqui um grupo de docentes que participaram da formação ofertada pelo Google. Os docentes fazem parte de uma Instituição de Ensino Superior ${ }^{5}$, localizada na Capital de Sergipe, no município de Aracaju, onde destacam-se as possibilidades e desafios do uso dos aplicativos propostos pelo Google para Educação.

Neste estudo, intentamos buscar respostas para o seguinte questionamento: como utilizar os aplicativos tecnológicos na formação inicial de professores de forma que possam contribuir para uma formação mais sólida frente à demanda da sociedade atual?

A natureza da pesquisa é qualitativa, com abordagem descritiva e exploratória, segundo Richardson (2012), com trabalho de campo. Para produção de dados foi adotado o questionário como instrumento semiestruturado, tendo os docentes como público-alvo. Já para analisar e interpretar os dados foi utilizada a perspectiva da análise de conteúdo, conforme Bardin (2016).

4 O omnibox é a "barra de endereço" do Google. Disponível em: https://support.google.com/chrome/answer/95426?co=GENIE.Platform\%3DDesktop\&hl=pt-BR. Acesso em: 10 de abril de 2019.

${ }^{5}$ Buscou-se não identificar a instituição atendendo ao pedido da mesma. 


\section{Os Apps do Google For Education no âmbito educacional}

Pensar em uma educação comprometida com a construção de uma sociedade mais igualitária e democrática nos remete a refletir sobre caminhos que se bem percorridos há grandes possibilidades de se ter esses anseios concretizados. Para isso, é preciso atentar à forma como se dá o acesso ao conhecimento, promovendo, no contexto escolar, problematização sobre as vantagens que as tecnologias digitais podem oferecer no processo de ensino e aprendizagem.

Assim, apoiando-se na conjuntura social de hoje, notada por significativas e rápidas mudanças advindas por meio das tecnologias, é preciso que os docentes entendam como esse recurso pode ser explorado para facilitar o acesso à informação e à produção de conhecimento de forma a promover mudanças.

Partindo dessa concepção educacional, compreendemos a importância e a necessidade da inserção das tecnologias em práticas de ensino. Dessa forma, a figura 01 (um) a seguir, mostra que, através do Google For Education, o professor tem à sua disposição diversos aplicativos de acordo com a sua intencionalidade e/ou do objetivo da disciplina para incorporar em seu planejamento de ensino. Vejamos as funcionalidades dos aplicativos do Google For Education na Educação. 
Figura 01 - Aplicativos do Google For Education e funcionalidades de uso no âmbito educacional

\begin{tabular}{|c|c|c|}
\hline $\mathbf{N}^{*}$ & Aplicativo & Funcionalidade \\
\hline 01 & Google Documentos (Docs) & $\begin{array}{l}\text { Processamento de texto. Criar e editar documentos de texto no navegador } \\
\text { sem precisar de um software dedicado. }\end{array}$ \\
\hline 02 & Google Drive & Serviço para armazenar e sincronizar arquivos \\
\hline 03 & Google Agenda & Agenda online integrada \\
\hline 04 & Google Sites & Ferramenta de criação de páginas na Web e wiki. \\
\hline 05 & Google Formulírios (Forms) & Criação de formulários personalizados \\
\hline 06 & Google Sala de aula (Classroom) & $\begin{array}{l}\text { Serviço gratuito para Instituições de Ensino e organizações sem fins } \\
\text { lucrativos e para qualquer usuário que tenha uma conta Google }\end{array}$ \\
\hline 07 & Google Keep & Serviço para fazer anotações \\
\hline 08 & Gmail & Serviço gratuito de webmail \\
\hline 09 & Google Planilhas & Processamento de planilha \\
\hline 10 & Google Apresentação & Criar e editar apresentações online \\
\hline 11 & $\begin{array}{l}\text { Hangouts } \\
\text { Passara a ser Google Meet }\end{array}$ & Plataforma de mensagens instantâneas e chat de video \\
\hline
\end{tabular}

Fonte: Elaborada pelos autores com base nas informações contidas no Google

Frente ao uso educacional dos aplicativos anteriormente listados, inferimos que eles podem propiciar melhorias para a qualidade de ensino, pois não só viabilizam, mas também incentivam o professor a pensar em propostas de ensino menos centradas em sua figura e fonte primária. Proporcionando maior interação e aberto ao diálogo, além de poder promover um ambiente colaborativo de aprendizagem, inclusive com produções individuais e coletivas de seus alunos, que ainda poderão ser publicadas no ambiente virtual do Google, viabilizando, segundo Mell (2011), o acesso público para diversos estudantes em qualquer lugar do mundo.

Com as tecnologias, o ensino passou a contar com vantagens que sinalizam para uma aprendizagem bastante promissora, de acordo com Kenski (2012), desde que sejam utilizadas adequadamente no processo de ensino e aprendizagem, tendo um objetivo claro de uso das 
mesmas. Portanto, a utilização de aplicativos nas práticas educacionais podem contribuir para melhorar os resultados de aprendizagem dos estudantes. Isto foi confirmado pelos professores participantes da pesquisa, ao serem indagados: quando você utiliza um aplicativo do Google For Education em sala de aula, nota diferença na aprendizagem da turma?

Asseveramos que com o Google for Education é possível o acesso e o desenvolvimento das tarefas independente de local/espaço, uma vez que não há obrigatoriedade de determinar o espaço físico do ambiente escolar como único "local" para o cumprimento das atividades e dos estudos. O importante com esses aplicativos é criar possibilidades para motivar os estudantes a aprenderem e a pensarem de forma autônoma e crítica. Portanto, faz-se necessário repensar a formação docente dentro do contexto do uso das TDIC em práticas de ensino que sejam cada vez mais desafiadoras.

\section{Formação Docente para o uso dos Aplicativos do Google For Education no Ensino Superior}

A política de formação docente no Brasil encontra-se legalizada na Lei de Diretrizes e Bases da Educação Nacional (LDBEN) n 9394/96, especificamente no artigo 62 (alterado pela Lei 13.415, de 16.02.2017), assim expresso,

[...] a formação de docentes para atuar na educação básica far-se-á em nível superior, em curso de licenciatura plena, admitida, como formação mínima para o exercício do magistério na educação infantil e nos cinco primeiros anos do ensino fundamental, a oferecida em nível médio, na modalidade normal (BRASIL, 1996).

No caput do artigo acima é possível entender que a formação docente está, inicialmente, sob a responsabilidade da instituição formadora. Daí a importância de os professores dos cursos de licenciaturas adotarem boas práticas de ensino para que os futuros professores possam consolidar experiências de aprendizagem inovadoras e que sejam possíveis de aplicação, claro, com adequações quando estiver em seu exercício profissional. Vejamos então o que está posto nos $\S 1^{\circ}, 2^{\circ}$ e $3^{\circ}$ do supracitado artigo,

$\$ \mathbf{1}^{\circ}$ A União, o Distrito Federal, os Estados e os Municípios, em regime de colaboração, deverão promover a formação inicial, a continuada e a capacitação dos profissionais de magistério.

$\$ \mathbf{2}^{\mathbf{0}}$ A formação continuada e a capacitação dos profissionais de magistério poderão utilizar recursos e tecnologias de educação a distância.

§ $3^{\circ}$ A formação inicial de profissionais de magistério dará preferência ao ensino presencial, subsidiariamente fazendo uso de recursos e tecnologias de educação a distância. (BRASIL, 1996). 
É notório, nos parágrafos acima, o registro importantíssimo sobre a inserção das tecnologias nos processos de ensino. O professor, em regência de turmas de licenciaturas que habilitam para a docência, precisa contribuir com o desenvolvimento de projetos de ensino que façam uso das TDIC, motivando o aluno a ter prazer em aprender e a ter vivências que possam ser mais tarde adequadas a outras situações de aprendizagem.

Portanto, e segundo Joly (2012), é necessária uma formação docente que oportunize reflexão crítica, planejamento e vivência com o uso educacional das TDIC em processos de ensino, pois só assim é possível que as tecnologias possam viabilizar oportunidades de construção de conhecimento.

Dessa forma é que neste trabalho intenta-se apresentar a formação docente para o uso dos aplicativos do Google for Education em sala de aula, através de uma pesquisa realizada em uma Instituição de Ensino Superior, no município de Aracaju-SE. Neste estudo, empregou-se o método de análise de conteúdo objetivando obter inferências a respeito do objeto de estudo, tentando se aproximar o máximo possível de sua realidade, pois, segundo Bardin (2016), as deduções lógicas ou inferências que são obtidas a partir das categorias responsáveis pela identificação das questões relevantes contidas no conteúdo das mensagens se aproximam do fato real estudado.

Assim, a pesquisa foi feita com 04 (quatro) professores/participantes, a fim de compreendermos se a formação que estão dando é propícia ao uso das TDIC em práticas de ensino pelos licenciandos quando estiverem em atividade docente. Os participantes apresentam os seguintes perfis:

Figura 02 - Informações gerais sobre os participantes

\begin{tabular}{|c|c|c|c|c|c|c|c|c|}
\hline \multicolumn{2}{|c|}{ SEXO } & \multicolumn{2}{|c|}{$\begin{array}{c}\text { FAIXA } \\
\text { ETÁRIA }\end{array}$} & \multicolumn{3}{|c|}{ TEMPO DE DOCÊNNCIA } & \multicolumn{2}{|c|}{$\begin{array}{l}\text { NÍVEL DE } \\
\text { ATUAÇÃo }\end{array}$} \\
\hline $\mathbf{M}$ & $\mathrm{F}$ & $\begin{array}{l}\mathrm{De} \\
30 \quad \mathrm{a} \\
40 \\
\text { anos }\end{array}$ & $\begin{array}{l}\text { De } 41 \\
\text { a } 50 \\
\text { anos }\end{array}$ & $\begin{array}{l}\text { De } 03 \text { a } \\
10 \text { anos }\end{array}$ & $\begin{array}{l}\text { De } 11 \text { a } \\
20 \text { anos }\end{array}$ & $\begin{array}{l}\text { Mais } \\
\text { de } 20 \\
\text { anos }\end{array}$ & Graduação & $\begin{array}{l}\text { Pós- } \\
\text { Graduação }\end{array}$ \\
\hline 01 & 03 & 01 & 03 & 02 & 01 & 01 & 04 & 04 \\
\hline
\end{tabular}

Fonte: Material organizado pelos autores de acordo com os dados coletados através do questionário aplicado no dia 23 de abril de 2019 
Pelo perfil apresentado, percebe-se características preponderantes de imigrantes digitais, tendo em vista que nenhum dos docentes é considerado nativo digital, um dos motivos que podem apresentar condições de uso das TDIC em sala de aula de forma mais tímida, ou seja, que não explorando todas as potencialidades disponibilizadas pelas tecnologias, nem tampouco pelo ambiente virtual do Google For Education. Entendendo neste contexto que nativo digital é, de acordo com Prensky (2012), estudantes que nasceram na era da tecnologia digital, e os imigrantes digitais são os docentes que estão se adaptando às tecnologias digitais, à era digital.

Ainda conforme os dados da tabela 02 , no que diz respeito ao tempo de docência, $50 \%$ dos participantes possuem menos de 10 anos de experiência de docência no nível superior, $25 \%$ apresentam até 20 anos de experiência e os outros 25\% mais de 20 anos. Destacamos que a maioria dos participantes tem até 10 anos de experiência em docência em várias instituições de ensino superior da rede privada e pública de ensino. Muito embora esse fato não seja considerado entrave para uma prática de ensino com a integração das TDIC, uma vez que o professor poderá incorporar as tecnologias em seu planejamento de ensino, conforme orientações legais previstas na própria LDBEN, mencionadas anteriormente. Observa-se também pelo perfil que todos os participantes ministram aulas para a graduação e pósgraduação, motivo pelo qual podem incorporar facilmente as TDIC em suas práticas, a fim de que possam identificar possibilidades de melhorias na educação, inclusive através da integração de forma planejada dos aplicativos educacionais.

Quando questionados se já passaram por formação para a utilização dos aplicativos do Google for Education para ser aplicado em sala de aula, 75\% dos participantes afirmaram ter participado e $25 \%$ relataram que não. Frente a isso, destacamos que deste total, $25 \%$ responderam ao seguinte questionamento: qual a frequência semanal de utilização dos aplicativos educacionais em sala de aula? afirmando que utilizam semanalmente em média duas vezes, enquanto os demais (75\%) utilizam sempre. Asseveramos que a maioria dos docentes que usam sempre os aplicativos da plataforma incorporaram o uso em seu cotidiano naturalmente, enquanto os demais somente em alguns momentos, o que nos leva a inferir a falta de apropriação tecnológica sobre os aplicativos existentes e suas funcionalidades para os mais diversos usos pedagógicos em sala da aula, conforme dados apresentados na tabela 03 a seguir.

Ainda de acordo as informações obtidas pelos discentes dos professores que utilizam no cotidiano os aplicativos e a plataforma, tem-se a possibilidade de adquirem maior experiência e apropriação tecnológica com o uso dessas tecnologias, tanto quanto podem 
melhor aplicá-las a favor em seu processo de aprendizagem, razão pela qual poderão dispor de boas condições de o fazer, inclusive no futuro, ao exercer sua prática docente, associando a utilização dos aplicativos educacionais de forma geral, além de poder proporcionar e incentivar maior autonomia e crítica em seus futuros alunos.

Vale ressaltar que ao se reportar aos aplicativos educacionais, especificamente os disponíveis através do Google for Education, os professores participantes utilizam conforme o percentual da tabela 03 a seguir:

Figura 03 - Aplicativos do Google for Education e percentual de professores que os utilizam no processo de ensino e aprendizagem

\begin{tabular}{|c|c|}
\hline $\begin{array}{c}\text { APLICATIVOS DO GOOGLE FOR } \\
\text { EDUCATIOM }\end{array}$ & $\begin{array}{c}\text { \% DE DOCENTE QUE OS } \\
\text { UTILIZAM }\end{array}$ \\
\hline $\begin{array}{c}\text { Google Agenda } \\
\text { Google Keep }\end{array}$ & $75 \%$ \\
\hline Google Classroom & $25 \%$ \\
\hline Blogger & $100 \%$ \\
\hline Google Meet & $0 \%$ \\
\hline Google E-mail & $25 \%$ \\
\hline Google Doc & $75 \%$ \\
\hline Google Planilha & $100 \%$ \\
\hline Google Site & $25 \%$ \\
\hline Outro & $50 \%$ \\
\hline
\end{tabular}

Fonte: Material organizado pelos autores de acordo com os dados coletados através do questionário aplicado no dia 23 de abril de 2019

Comparando as informações descritas anteriormente com uma das respostas obtidas de um dos professores participantes da pesquisa ao questionamento: quais as possibilidades e potencialidades do uso desses aplicativos em sala de aula?

É possivel entender o porquê do Google Classroom e o Google Doc aparecem em record de uso pelos docentes e, em segundo lugar o Google Agenda e o Google E-mail, pois, são os aplicativos que melhor permitem uma aprendizagem ubíqua.

Corroborando com o pensamento do professor em formação, fica evidente a necessidade de ter contato com as TDIC em seu processo de aprendizagem para que possa desenvolver competências e habilidades, além de novas estratégias metodológicas que 
viabilizem o novo formato de planejamento de suas aulas, apoiadas numa pedagogia construtivista com foco no aprendizado do aluno, e não mais no professor, podendo ainda promover aprendizagem colaborativa através do acesso à internet por meio de dispositivos móveis.

\section{Considerações finais}

Destarte o que já foi apresentado, consideramos que, para se utilizar os aplicativos do Google ou até mesmo qualquer tipo de tecnologia digital e/ou ferramenta digital de maneira assertiva no âmbito educacional, como relatado pelos docentes participantes da pesquisa, fazse necessário uma formação continuada que abranja as possibilidades de uso dessas ferramentas. Fica demonstrado assim que a formação continuada faz diferença nos resultados da prática.

Além da formação e preparação dos docentes para utilização adequada das TDIC no processo de ensino, outro fator primordial foi o interesse dos docentes em querer aprender e apropriar-se tecnologicamente de maneira que, ao utilizá-la, possam extrair o máximo de suas potencialidades, apesar de não serem considerados nativos digitais devido a sua faixa etária.

Assim, esta pesquisa aponta que o interesse em melhorar sua prática por parte do docente e o investimento numa formação continuada para esses tornam-se essenciais para a melhoria do processo educativo em prol de uma qualidade no ensino e são objetivos a serem alcançados pelos envolvidos.

\section{REFERÊNCIAS}

BARDIN, L. Análise de conteúdo. Trad. Luís Antero Reto e Augusto Pinheiro. São Paulo: Edições 70, 2016.

BRASIL. Lei n. 9.394, de 20 de dezembro de 1996. Lei de Diretrizes e Bases. Diário Oficial da União, Brasília, Seção 1, p. 27833, 23 dez. 1996. Disponível em:

http://portal.mec.gov.br/index.php?option=com_content\&view=article\&id=12907:legislacoes \&catid=70:legislacoes. Acesso em:29 março de 2019 .

JOLY, M. C. R. A.; SILVA, B. D.; ALMEIDA, L. da S. Avaliação das competências docentes para utilização das tecnologias digitais da informação e comunicação. Currículo sem Fronteiras, v. 12, n. 3, p. 83-96, set./dez. 2012.

KENSKI, V. M. Educação e tecnologias o novo ritmo da informação. 8. ed. Campinas, SP: Papirus, 2012. 
MELL, P. et al. The NIST definition of cloud computing. National Institute of Standards and Technology, special publication 800-145, set. 2011. Disponível em:

https://nvlpubs.nist.gov/nistpubs/legacy/sp/nistspecialpublication800-145.pdf. Acesso em: 21 set. 2018. DOI: https://doi.org/10.6028/NIST.SP.800-145

PRENSKY, M. Homo sapiens digital: dos imigrantes e nativos digitais à sabedoria digital.

Conectados no ciberespaço. São Paulo: Paulinas, 2012. p. 101-116.

PRENSKY, M. Nativos digitais, imigrantes digitais. On the horizon, v. 9, n. 5, p. 1-6, 2001.

RICHARDSON, R. J. Pesquisa social: métodos e técnicas. 3. ed. 14. Reimpr. São Paulo:

Atlas, 2012.

\section{Como referenciar este artigo}

VASCONCELOS, A. D.; FERRETE, A. A. S. S.; LIMA, I. P. de. Formação docente para o uso dos aplicativos do Google for Education em sala de aula. Revista Ibero-Americana de Estudos em Educação, Araraquara, v. 15, n. 4, p. 1877-1887, out./dez. 2020. e-ISSN: 19825587. DOI: https://doi.org/10.21723/riaee.v15i4.12741

Submetido em: 17/07/2019

Revisões requeridas em: 30/10/2019

Aprovado em: 20/02/2020

Publicado em: $30 / 08 / 2020$ 